\title{
O significado de ser pai na ótica de casais grávidos: limitações e facilidades
}

The meaning of being a father from the perspective of pregnant couples: strengths and weaknesses

El significado de ser padre en la óptica de parejas embarazadas: limitaciones y facilidades

Maria de Fátima Mota Zampieri ${ }^{1}$, Joice Cristina Guesser², Beatriz Belém Buendgens ${ }^{3}$, Jerusa Mendes Junckes ${ }^{4}$, Ingrid Gonçalves Rodrigues ${ }^{5}$

\section{RESUMO}

Pesquisa qualitativa com cinco casais grávidos, visando conhecer o significado de ser pai, os aspectos limitantes e favoráveis neste processo. Os dados foram coletados por meio de entrevistas e depoimentos durante as visitas e prática educativa. Após análise emergiram dois significados de "ser pai": pai provedor da família, pai afetivo e envolvido com o processo de nascimento e filhos. A participação do pai deu-se em função da sua disponibilidade e presença em grupos educativos, do estímulo da mulher e dos profissionais. Os fatores limitantes foram: machismo, trabalho, desconhecimento dos direitos, oposição das mulheres, despreparo dos profissionais e atividades educativas insuficientes. Conclui-se que, na medida em que o homem se envolve com a gravidez, companheira e filho, ele constrói e sedimenta o papel de pai, favorecendo o desenvolvimento psicoafetivo do filho. $\mathrm{O}$ apoio e abertura das mulheres e dos profissionais são fundamentais. $\mathrm{O}$ estudo pode subsidiar mudanças nas práticas de saúde.

Descritores: Paternidade; Enfermagem; Educação em Saúde; Gestação; Pai.

\section{ABSTRACT}

Qualitative study performed with five pregnant couples to identify the meaning of being a father and the strengths and weaknesses of the aspects involved. Data were collected through interviews. The analysis revealed two meanings: being the breadwinner, and the affective father involved with the birth and his children. The fathers' participation depended on their availability and presence in the educational groups, and on the encouragement to participate from wives and health professionals. The identified weaknesses were: male chauvinism, need to work, lack of knowledge regarding their rights, wife's opposition, lack of preparation of health professionals, and insufficient educational activities. When a man becomes involved with the pregnancy, wife and child, he builds and establishes the role of father, benefiting the pscyho-affective development of his child. Support and welcoming on behalf of the wife and health professionals are essential. This study may serve as support to changing health practices.

Descriptors: Paternity; Nursing; Health Education; Pregnancy; Fathers.

\section{RESUMEN}

Investigación cualitativa con cinco parejas embarazadas, objetivando conocer el significado de ser padre, los factores limitantes y favorecedores de este proceso. Datos recolectados mediante entrevistas y testimonios durante visitas y práctica educativa. Del análisis, emergieron dos significados de "ser padre": padre proveedor de la familia y padre afectivo involucrado con el nacimiento y los hijos. La participación paterna es proporcional a su disponibilidad y presencia en grupos educativos, estímulo de la mujer y los profesionales. Los factores limitantes fueron: machismo, trabajo, desconocimiento de derechos, oposición de las mujeres, incapacidad de los profesionales e insuficiencia de actividades educativas. Se concluye que en medida en que el hombre se involucra con el embarazo, compañera e hijo, se construye y cimenta el papel de padre, favoreciéndose el desarrollo psico-afectivo del hijo. El apoyo y apertura de la mujer y profesionales son fundamentales. El estudio puede ayudar a cambios en las prácticas de salud.

Descriptores: Paternidad; Enfermería; Educación en Salud; Embarazo; Padre.

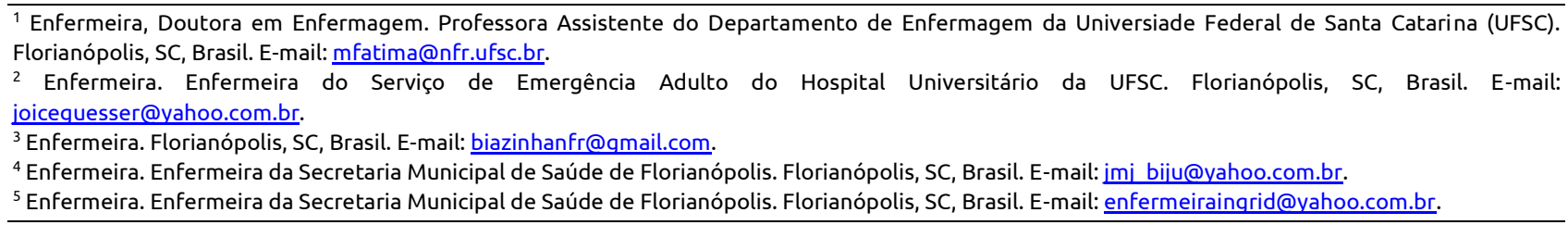




\section{INTRODUÇÃO}

A gravidez é um período de intensas transformações físicas, psicológicas e sociais na vida da mulher grávida e do futuro pai. A experiência de ter um filho inaugura um momento importante no ciclo vital da mulher e do homem: emerge uma nova mulher, um novo ser, um novo pai e uma nova família(1). A mulher e o homem assumem o compromisso e a responsabilidade pela vida e pelo bem estar de um novo ser, situam-se como pai e mãe e apresentam novas expectativas, sensações, dúvidas, típicas e singulares da gestação, do parto e pósparto(2).

Da mesma forma como a maternidade pode ser considerada uma situação de crise, a paternidade configura-se como uma situação crítica no desenvolvimento emocional do homem, gerando ora crescimento, realização, amadurecimento, ora frustração e desestruturação(1). O medo, as incertezas, o impacto diante das mudanças e das responsabilidades advindas da possibilidade de ter um filho e ser pai, levam o homem a viver uma situação conflituosa e ambígua, em que coexistem a felicidade, a satisfação, a insatisfação, o medo e a insegurança ${ }^{(1-2)}$.

Durante anos, seguindo a lógica de uma sociedade patriarcalista, construída culturalmente, o homem ocupou o espaço público, distanciando-se do convívio familiar e da trama doméstica, constituída fundamentalmente pela mulher e criança. O homem foi educado para prover a família e a mulher para cuidar dos filhos e educá-los. Este modelo, caracterizado pela rígida divisão de papéis sexuais, consolidado pela família nuclear burguesa, ainda é uma realidade nos dias de hoje, sobretudo no que se refere às famílias com menor poder aquisitivo, sendo o trabalho doméstico e os cuidados com os filhos ainda conferidos às mulheres, mesmo quando estas participam ativamente na economia familiar ${ }^{(3-4)}$.

A despeito disto, percebe-se que na atualidade 0 papel atribuído aos homens e às mulheres vem sofrendo significativas transformações de cunho social. A mulher vem ocupando espaços importantes no mercado de trabalho. Em função disso, novos arranjos familiares se estabeleceram com significativas mudanças nas relações entre homens e mulheres, resultando na promoção de maior equidade nos papéis de gênero ${ }^{(2,5)}$.

Um novo conceito de pai e novas formas de exercer este papel estão presentes na contemporaneidade, no entanto, durante essa fase de adaptação, as responsabilidades sociais impostas ao pai provedor ainda continuam sendo exigidas ao homem, gerando incertezas e incompreensões ${ }^{(6)}$. Assim, a questão da paternidade deve ir além dos limites da família, tornando-se um tema relevante de discussão no âmbito da saúde sexual, reprodutiva e coletiva, necessitando aprofundamento e estudos ${ }^{(2)}$.

Além disso, as evidências científicas reforçam que é fundamental a presença do pai no processo de nascimento desde a gestação para o estabelecimento dos vínculos entre pai e bebê, fortalecimento da paternidade, promoção da saúde mental do filho e bem estar da mulher, levando os pais a repensarem e discutirem sua identidade social com vistas a uma participação mais ativa no exercício da paternidade ${ }^{(4-5,7-}$ 8). Estas questões também geram por parte destes e dos profissionais, a necessidade de maior compreensão sobre o significado da paternidade.

No âmbito da atenção à saúde, em nível primário, apesar dos esforços de alguns profissionais, observa-se que a inclusão do pai no processo de nascimento, mesmo com avanços legais e políticas públicas adotadas, ainda precisa ser conquistada em determinados espaços e sedimentada em outros. Evidenciam-se, neste nível de atenção, barreiras sociais e pessoais que podem dificultar a participação do pai e o exercício de sua paternidade. Os homens são "invisíveis" nos diversos programas públicos de saúde, mesmo após a divulgação da Política Nacional de Atenção Integral à Saúde dos Homens. Permanece difundida a ideia de que as unidades básicas de saúde são serviços direcionados para mulheres, crianças e idosos ${ }^{(9-10)}$.

Na literatura, mesmo havendo estudos sobre a paternidade(11), observa-se uma escassa produção acadêmica nacional sobre o significado da paternidade na ótica de casais grávidos que vivenciam este processo.

Assim, as mudanças nas configurações familiares e nas relações de gênero em que se insere a paternidade; a importância da figura paterna para o desenvolvimento cognitivo e comportamental do filho; a necessidade de dar maior visibilidade ao papel do pai na atenção básica para direcionar a assistência, reforçam o interesse social e acadêmico de se compreender o significado de ser pai na ótica dos casais grávidos, justificando a realização deste estudo.

Considerando o exposto, buscam-se respostas para 
as seguintes perguntas de pesquisa:

Qual o significado e a importância de ser PAl para os casais? Quais os limites e as possibilidades para a participação e inserção do PAl na gestação nos Centros de Saúde?

Para responder tais questões, estabelecemos como objetivos deste estudo conhecer o significado de ser pai no processo de nascimento e identificar os fatores limitantes e favoráveis a esta participação na gestação, no parto e pós-parto, na ótica dos casais grávidos.

\section{MÉTODOS}

Pesquisa qualitativa na modalidade convergenteassistencial. Utilizada amplamente na área de saúde, tal pesquisa procura minimizar, solucionar problemas, realizar mudanças, introduzir inovações no cotidiano do cuidado, enfatizando o pensar e fazer em conjunto. Nela, pesquisadores e pessoas envolvidas na situação pesquisada constroem uma relação de cooperação mútua, pesquisando e cuidando(12).

O estudo foi desenvolvido em 2009 e 2010 em um Centro de Saúde (CS) de Florianópolis durante as práticas educativas realizadas nas consultas pré-natais, no grupo de casais grávidos e nas residências dos participantes, por meio das visitas domiciliares.

Os critérios para inclusão dos sujeitos na pesquisa foram: ser gestantes de baixo risco, usuária do centro de saúde, estar acompanhada por seu parceiro e ter interesse em participar. O número de participantes dependeu do tempo destinado ao estudo e da saturação dos dados, ou seja, os dados foram considerados suficientes quando passaram a se repetir.

Os dados foram coletados por meio de entrevista semiestruturada, desenvolvida no domicílio, e de depoimentos oriundos das consultas pré-natais, visitas domiciliares e do grupo de casais grávidos, cenário onde se desenvolveu a prática educativa. Essa prática constou de quatro etapas ${ }^{(13)}$ : a) descobrindo-se, que consistiu da apresentação dos participantes e da proposta de pesquisa; b) desvelando a situação, na qual se identificaram as necessidades do casal, os significados de ser pai e as formas de participação; c) propondo e agindo, que permitiu trabalhar a situação desvelada, teorizando-a; d) revendo e redirecionando, que incluiu a avaliação e adoção de novas estratégias. Os depoimentos e as entrevistas foram gravados e registrados manualmente por um dos pesquisadores, mediante consentimento prévio e posteriormente transcritas.

Os dados coletados foram classificados e organizados, a partir de uma abordagem descritiva e reflexiva e analisados seguindo as três etapas propostas por Minayo ${ }^{(14):}$ 1) ordenação dos dados; 2) classificação dos dados. Após leitura aprofundada dos materiais transcritos, recortaram-se do conjunto de dados, as unidades de registro ou temas referentes aos fenômenos, que agrupados por convergência e relação de ideias deram origem às categorias; 3) a análise final consistiu do confronto do material empírico e fundamentação teórica, gerando novas compreensões e interpretações sobre o tema ${ }^{(14)}$. Durante esta prática educativa estabeleceram-se interações, transações, que passarão a influenciar a percepção dos participantes, ajudando-os na construção de seus papeis.

O estudo segue os princípios da Resolução 196/96, sendo aprovado pelo Comitê de Ética de Pesquisa com Seres Humanos da Universidade Federal de Santa Catarina e autorizado pela Secretaria de Saúde do Município sob o número de protocolo 176/08. Os participantes assinaram o Termo de Consentimento Livre e Esclarecido (TCLE), sendo mantido o anonimato por meio de pseudônimos. Para tanto, usou-se nomes de animais, cujos machos participam no cuidado da prole.

\section{RESULTADOS E DISCUSSÃO}

Participaram do estudo cinco casais, gestantes e seus companheiros. A faixa etária dos homens variou entre 23 a 36 anos e a das mulheres de 20 a 31 anos. Oito participantes tinham o ensino médio, um o ensino fundamental e um o ensino superior. Três casais eram casados e um era unido consensualmente, sendo que três planejaram a gravidez. Quanto ao número de gestações, quatro eram primíparas. A idade gestacional no início da pesquisa variou de nove a 28 semanas.

Neste processo, as categorias oriundas dos discursos dos participantes foram: a) significado de ser pai; b) confrontando-se com o novo rumo à paternidade, com as subcategorias: o impacto diante da gravidez e preparando-se para a paternidade; c) limitações para a participação do pai no processo de nascimento; d) oportunidades para inclusão do homem. 


\section{Significado de ser pai}

Рara os envolvidos neste estudo "ser pai" apresenta dois significados que se mostram complementares e, por vezes, antagônicos: pai afetivo, cuidador e educador e o segundo, o pai provedor.

Ser pai é ser afetivo, participar, fazer parte da rede de apoio à mulher e companheira, dividindo tarefas, tendo paciência, procurando transmitir tranquilidade, atenção, segurança e amor, como reforçam os depoimentos.

O papel do pai é dar apoio já na gestação. No parto, só estar do lado já ajuda. Dá mais tranquilidade e conforto para mãe. No pós-parto ele pode ajudar com o bebê. (Mãe Peixe Palhaço).

Tu saberes que o pai está ali junto, dando toda a assistência que tu precisas. Eu quero ser o primeiro ver ele nasce (Pai Peixe Palhaço).

Indo as consultas, aprendendo a ter mais paciência (Pai Lobo Guará).

Participar é estar junto com a mãe e bebê todas as horas (Pai Cavalo Marinho). Estar sempre ali, bem parceiro (Mãe Pinguim).

O acompanhamento da gestante durante a consulta pré-natal, o companheirismo, os cuidados com a gestante e criança fazem parte do comportamento atualmente assumido por alguns homens diante da paternidade ${ }^{(5,7)}$. A experiência masculina na atenção prénatal tem aberto espaços para novas relações de gênero, nas quais o homem e mulher participam e cuidam do filho(15). Estes sujeitos sociais afastam-se do modelo rígido e tradicional, participam efetivamente da gravidez, procuram se vincular com o bebê intraútero, compartilham as alegrias após o nascimento e as tarefas diárias reservadas outrora apenas à mulher(2).

Pai, segundo alguns participantes, é aquele que presta cuidados, aconselha, mostra os caminhos, educa, estabelece limites, dá amor e atenção ao longo da trajetória da vida. Ser pai, revelaram os dados, implica criar e educar, estabelecer laços afetivos independente da consanguinidade. É estar presente; é uma experiência marcante e única na vida de um homem, especialmente quando este participa e se sente grávido. É um momento de crescimento pessoal e amadurecimento para o homem, que o permite repensar seus objetivos e suas perspectivas de vida. Isto se evidencia nos relatos:
Pai é o que cuida, educa, dá carinho, ensina a viver? (Pai Peixe Palhaço).

É quem cria; quem educa, não é apenas quem faz. Fazer, acho, é o mais simples da coisa. Pai é um ser supremo? (Pai Cavalo Marinho).

Ser pai é uma benção. Acho que essa criança vai curar minhas angústias, me amadurecer (Pai Lobo Guará). Se não tem pai, não tem família.

Neste sentido, segundo a literatura, se os pais participarem e definirem conjuntamente como eles querem educar seus filhos, estes estarão reforçando os seus papeis sociais e mostrando aos filhos um modelo de crescimento saudável e harmonioso para que possam viver a vida adulta de forma mais estruturada e feliz ${ }^{(5)}$.

A paternidade, como afirmam as Mães Lobo Guará e Pinguim, tem o mesmo valor que a maternidade, já que o homem e a mulher apresentam sentimentos semelhantes de felicidade e de medo e ajudam na educação dos filhos.

A mãe e o pai são importantes na mesma proporção. (Mãe Lobo Guará).

O pai tem que ser o alicerce da casa, da família. Tem que dar amor, mas saber repreender quando necessário (Mãe Pinguim).

A presença do pai na vida de um filho é tão fundamental quanto a presença da mãe quando se pensa em um bom desenvolvimento socioemocional da criança, pois ambos assumem papeis complementares, atuam com autoridade e compartilham afetos ${ }^{(5)}$.

Nesta perspectiva, emerge uma nova compreensão de ser pai, identificado com as exigências contemporâneas da família, aquele que protege a esposa e mostra-se presente desde a gestação, expõe sua face afetiva, solidária e próxima da intimidade cotidiana. Esse novo pai rompe com o modelo tradicional de paternidade e favorece a construção do trinômio paimãe-filho(2). Neste desenho social e familiar, ambos compartilham tarefas educativas e de organização do cotidiano. Ambos têm o direito de expor seus sentimentos sem necessitar se afirmarem sexualmente. Essa proposta reduz a responsabilidade do homem pela manutenção familiar e o aprisionamento ao trabalho, oportunizando a ele se aproximar da família, além de 
desvanecer o antigo papel da mulher de protetora e cuidadora, dando lugar ao de companheira(2).

Esta revolução paternal e maternal ainda na fase da adolescência pode levar anos para se concretizar plenamente, implicando mudanças de hábitos e de valores sociais. O exercício da paternidade pode ser a porta de entrada do homem no campo dos cuidados, de si e dos familiares(2). Para tanto, é preciso superar construções sociais e de gênero estabelecidas pela sociedade patriarcal.

Além deste significado, opondo-se ou somando-se a ele, "ser pai" também foi compreendido pelos participantes como ser um homem forte, o exemplo, e, sobretudo o provedor financeiro, que tem a responsabilidade de sustentar a família e a casa. Muitas vezes, por conta disto o homem se distancia da gravidez, do parto e coloca em segundo plano a educação dos filhos. Os depoimentos reforçam a assertiva:

...tipo assim, quando eu soube que ia ser pai eu já queria arrumar outro emprego (Pai Pinguim).

Ele tem que estar forte para poder sustentar ela, procurar um meio para resolver (Pai Peixe Palhaço).

Este modo de pensar o papel e significado de "ser pai" foi culturalmente transmitido e se perpetuou de geração em geração, foi reproduzido inclusive pelas mulheres que tinham sob sua responsabilidade a educação dos filhos. Essas agentes foram decisivas na esfera da reprodução social, uma vez que elas repassavam aos filhos as ideologias vigentes na sociedade $^{(2,7,9)}$.

A introdução da mulher no mercado do trabalho, o estabelecimento de novas relações entre o homem e a mulher e a cobrança social para que os homens expressem um comportamento mais participativo e envolvente nos relacionamentos afetivos e familiares, têm modificado o papel do pai na sociedade e aberto oportunidades para a inserção do homem no processo de nascimento que conjugam os dois significados ${ }^{(11,16)}$. Assim, o "novo pai" ainda está em construção, visita e convive com o pai tradicional, aproximando-se ou afastando-se dele, ampliando o significado de paternidade ${ }^{(2,11)}$. Neste processo, o homem vem tentando viver a experiência de ser pai através do rompimento de estereótipos do passado. Ele procura refletir e redefinir seu papel, restabelecer seu lugar e repensar modelos que the permita viver a paternidade $^{(11,17)}$.

\section{Confrontando-se com o novo, rumo à paternidade.}

Esta categoria é subdividida em duas subcategorias: a) impacto diante da gravidez e, b) preparando-se para a gravidez.

\section{Impacto diante da gravidez}

Com a descoberta da gravidez o homem vivencia sentimentos ambivalentes e contraditórios que podem se acentuar quando a gravidez não é planejada ou aceita, conforme os depoimentos:

No início eu fiquei apavorado, mas depois, comecei a me acostumar (Pai Pinguim). Vontade de matar, porque a gente sempre se cuidou. Só que ela deu uma relaxada, mas depois, foi normal. Fui me acostumando com a ideia. Faz tempo que eu quero ter um filho, mas queria que fosse planejado. Atropelou tudo!!! Mas foi tranquilo. Meus sentimentos agora são de amor e carinho (Pai Peixe Palhaço).

A mistura de sentimentos e os conflitos dos homens ampliam-se em decorrência das alterações físicas e emocionais ocorridas com a sua companheira, nem sempre compreendidas por eles, e de seus próprios medos frente ao novo papel na sociedade, mudanças de ritmo de vida e responsabilidades implícitas neste momento, como reforça "Pai Lobo Guará".

Sinto-me com mais responsabilidade, um peso a mais. $\dot{E}$ uma mistura: feliz, preocupado, angustiado.

A paternidade é permeada por conflitos, determinados pela situação nova que o casal vivencia. Misturam-se sentimentos de alegria, tristeza, satisfação e insatisfação. Questões culturais, sociais, religiosas e familiares permeiam a vivência da paternidade, definindo-a como experiência desejada ou não desejada, desejável ou não desejável e ditam como será estabelecida a relação entre homem-mulher e deste com o filho. Além da proximidade física com a gestante, o envolvimento afetivo e aceitação da gravidez são fundamentais para que o homem se sinta pai antes do nascimento $^{(2)}$. 
Reforçando a questão de gênero, alguns homens expressam um sentimento de conquista e de vitória por poderem confirmar sua masculinidade e contribuir para perpetuar a espécie, percebido nas entrelinhas desta fala.

Então, quando ela me mostrou o exame. Foi muito louco, foi massa mesmo. Acertei "porra" (Pai Cavalo Marinho).

A paternidade surge como um desejo que se estabelece em um determinado momento da trajetória de vida, o casamento, e está voltada para o futuro, para a descendência. Ter um filho, para os homens, concretiza a virilidade heterossexual(17), o cumprimento de uma função social, a reprodução da espécie(2).

\section{Preparando-se para a paternidade}

No início da gravidez os homens não percebem o bebê e seus movimentos. Segundo os entrevistados, percebem-se pai, a partir dos sentimentos e sensações de sua mulher, envolvendo-se e identificando-se com ela. Eles apresentam inclusive alterações como o aumento da sensibilidade e enjoo como falam o "Pai Avestruz" e o "Pai Pinguim".

É um sentimento diferente assim.....de felicidade. [...] dá um frio na barriga, a gente fica mais sensivel.

Às vezes eu tenho a impressão de que eu estou grávido também. (Pai Pinguim).

Os pais buscam estabelecer vínculos com o bebê, imaginando como ele será, procuram aproximar-se dele, conhecê-lo, amá-lo, já durante a gravidez. A preocupação com a companheira e sua saúde é tão intensa que ele pode sufocá-la como relata a Mãe Peixe Palhaço. Por outro lado, este cuidado revela carinho e amor.

Ele me dá apoio, mas ele me assusta. [...] No início não caiu a ficha; agora ele só me paparica; cuida se estou comendo, pega no meu pé. Os exageros me incomodam (Mãe Peixe Palhaço).

Com o evoluir da gravidez, quando o homem compartilha sentimentos relativos à gravidez com sua companheira, fica ao lado dela, acompanha a consulta de pré-natal, participa nos grupos e, principalmente, quando passa a perceber os movimentos do bebê, escuta os batimentos e o visualiza por meio do ultrassom, vai se "dando conta", sedimentando a ideia de ser pai como aconteceu com o Pai Guará e Pinguim.

A cada dia coisas novas vão acontecendo. Preocupações que tu não tinhas com dois meses, tu tens com cinco. Ouvi o coração dele e chorei. A hora que eu vi ele se mexendo... (Pai Pinguim).

Parecia que ele queria evitar ir às consultas e exames. Ele foi vendo que era normal. Ouviu o coração, viu na telinha, foi se acalmando (Mãe Lobo Guará).

Este processo vai se concretizando quando o homem interage com o filho por meio do toque, do pensamento e da fala, estabelece vínculos já na gravidez, como evidencia o relato da "Mãe Cavalo Marinho":

[...] É ele sente timidez de falar com o bebê. No comecinho pelo fato de ele não sentir mexer, acho que ele ficava meio atrapalhado. Às vezes, ele chegava, beijava, mas eu via que ele se achava meio bobão. Ele nunca falou para mim, mas eu percebia. [...] Depois que falaram sobre as músicas, ele ficou um tempão, selecionando as letras. Escolheu várias músicas para nossa filha. Quando chega do trabalho, ele me leva e fica cantando, fica pondo e conversando com a barriga.

Assim, o envolvimento paterno na gestação não se restringe a adoção de comportamentos como acompanhar consultas e exames, mas inclui o vínculo emocional com a mulher e o filho, que varia de acordo com o desenvolvimento do bebê e as características de cada pai. Ao longo da gravidez, o grau de envolvimento vai mudando, constituindo três fases: a primeira, que vai desde a suspeita de gravidez até a sua confirmação, é acompanhada de um grande impacto inicial, podendo gerar reações de desconforto, estresse e ambivalência. Na segunda fase, até que os sinais de gravidez não sejam evidentes, há um distanciamento emocional do pai. Na última fase, especialmente no ultimo trimestre, os homens vivenciam a gestação como real e importante em suas vidas, conseguindo definir-se como pais, tornando-se mais participativos ${ }^{(9)}$. A gestação funciona para os pais como um período de preparação para que possam assumir os novos papeis e as demandas após o nascimento do bebêt(9). 
Neste momento, inicia um movimento para transpor desse estado imaginário para o concreto e abre-se um caminho para o exercício da paternidade, mas nem sempre o homem consegue fazê-lo na sua totalidade. Assim, como para algumas mulheres o sentimento de ser mãe só desperta na medida em que estas conhecem e interagem com seus filhos, muitos pais só se sentem realmente pais quando os filhos nascem e eles podem envolvê-los nos braços. Tal sentimento é evidenciado pela maioria dos participantes do estudo e pode explicar o distanciamento inicial de alguns deles na gravidez e em todo o processo de nascimento.

Ultrassom [...] não, no dia, mas só que é assim, ainda não consegui (ver-se como pai). Aí, depois que vi o negócio crescendo, então falei: ah!! Bom, realmente [...] então, quando ela me mostrou o exame. Foi muito louco, foi massa mesmo (Pai Cavalo Marinho).

Não tem como sentir o que eu sinto, está crescendo dentro de mim (Mãe Pinguim).

Não sei, é tudo muito estranho. A gente vai lá vê barriga, vê que mexe, vê ultrassom e tal, mas tipo a ficha ainda meio que não caiu, sabe? Eu acho que só depois que nascer mesmo, é que vou crer (Pai Peixe Palhaço).

Segundo alguns autores, a formação do vínculo entre pai e filho costuma ser mais lenta e se consolida gradualmente após o nascimento e desenvolvimento da criança, por maior que seja a participação deste em todo esse processo. Para eles, é impossível compartilhar tudo, pois as vivências femininas não são idênticas as masculinas. Mesmo após a chegada do filho, o sentimento de paternidade ainda não é tão perceptível para alguns homens, assim como o peso da responsabilidade que esse evento pressupõe $\mathrm{e}^{(1-2,9)}$.

\section{Limitações para participar}

Em que pese o interesse e a procura dos pais de espaços permeáveis na família, nas instituições de saúde e na sociedade para se incluírem e participarem ativamente durante todo o processo de nascimento, este movimento ainda é lento e não atinge toda a população masculina, contribuindo para tal alguns fatores limitantes.

O trabalho foi o entrave mais citado. A questão da sobrecarga de trabalho e o cansaço dele decorrente, os horários de trabalho coincidentes com as consultas e grupos educativos; e, especialmente, a visão e o comportamento dos empregadores que não valorizam a importância da participação do homem na atenção prénatal, foram os fatores mais limitantes. 0 desconhecimento dos direitos pelos homens e a forma de alcançá-los, bem como a falta de informações corroboraram com este quadro, como expressa a fala:

Um dos fatores é isso mesmo, o trabalho, as empresas enxergam que a mãe tem mais direito de sair para as consultas pré-natal e o pai nem tanto. A gente vê isso no grupo porque são pouquíssimos pais que podem participar. Carga de trabalho, cansaço. Teve dia que nem dormi para levá-la ao exame (Pai Lobo Guará).

Os horários de trabalho no mesmo horário da consulta de pré-natal impedem a inclusão e participação dos pais neste momento ${ }^{(7,18)}$. Os pais muitas vezes ficam presos ao seu papel de provedor, apesar do interesse em participar mais efetivamente do processo de nascer e das atividades que envolvem a gestação, perdendo esta oportunidade única em sua vida ${ }^{(19)}$.

O machismo, reforçado pela família, também é um fator impeditivo para que os homens participem do processo de nascimento. As pressões exercidas pelos familiares e amigos reforçam o papel de cuidadora da mulher e o de provedor do pai e deixaram subliminarmente a ideia de que se homem assume prerrogativas femininas não está agindo como homem, como reforçam os depoimentos.

Tem também muito machismo. Preciso corrigir muita coisa, mas tem gente mais machista que eu. Talvez por isso não participa... para manter a pose... porque isso é coisa de mulher (Pai Cavalo Marinho).

Trabalho, amigos falando (machismo), família que diz que não tem necessidade de ir ao pré-natal e ultrassom (Mãe Peixe Palhaço).

Alguns homens ainda possuem reservas quanto a sua participação neste processo, encontrando-se fortemente arraigada a isso a ideia de que o amor e o cuidado com os filhos, mesmo na gestação, são basicamente responsabilidades femininas. Em função das pressões sociais por medo de perderem a imagem socialmente construída de "macho", acomodam-se em situações que thes dão certa estabilidade ${ }^{(17)}$. 
A postura ambivalente da mulher, ora dando espaço e até pressionando para participar, ora restringindo a participação do homem, mesmo que de modo velado também transpareceu. Para algumas mulheres que sempre foram educadas para cuidar dos filhos, compartilhar nem sempre é fácil, constituindo-se um fator de conflito e de perda de poder.

Eu estimulo sim, acho que até demais, porque às vezes eu cobro. Eu fico. Amor fala com o teu filho, dá boa noite. Pego muito no pé (Mãe Pinguim).

Para que os homens experienciem a paternidade é necessário que estes e as mulheres reflitam e repensem seus atributos sociais no processo de nascimento e reconheçam a paternidade como uma oportunidade para que os homens ampliem suas dimensões internas e renovem sua relação com a vida(2).

Em relação à atenção prestada nas instituições de saúde alguns obstáculos se destacaram, entre eles: a falta de estímulo do cento de saúde à participação do pai, a descontinuidade e a reduzida oferta de atividades educativas grupais e a falta de divulgação destas na comunidade. Os discursos que seguem reforçam isto.

O posto deveria dar um incentivo para fazer um encontro de casais, igual ao que vocês tão fazendo. (Mãe Lobo Guará).

Eu acho que esse grupo deveria ser um grupo ativo de gestante, porque eu acho maravilhoso isso. A única coisa que o posto facilita é poder participar das consultas, eu não conheço mais nada (Mãe Pinguim).

O posto não colabora, nem atrapalha. Não tenho ideia sobre o que poderia ser feito para melhorar (Pai Lobo Guará).

Durante muito tempo os serviços de saúde priorizaram a atenção à saúde da mulher e da criança, considerados grupos vulneráveis, distanciando-se do homem. O homem por sua vez não procurava o serviço. Assim, nem o profissional procurou aperfeiçoar-se para cuidar do homem e nem este reivindicou este cuidado. Na área obstétrica houve um avanço neste sentido, trazendo o homem para o cenário do nascimento e para o serviço de saúde. No entanto, nem todos os profissionais têm esta visão. O despreparo dos profissionais pode ser considerado um empecilho para inserção do pai na gravidez e parto, sendo necessário que estes se capacitem e compreendam esta nova forma de cuidar, inserindo o homem também como protagonista no processo de nascimento(17).

\section{Oportunidades para inclusão do homem}

Рага superar as dificuldades encontradas e transpor este período do desenvolvimento humano, alguns pais estão buscando espaços de atuação, oportunidades e possibilidades para se preparar para o exercício da paternidade.

A transição do pai tradicional para um novo pai mais participante e inserido no processo de nascimento pode ser acelerada e motivada, segundo os depoimentos por alguns fatores: acesso e ampliação de informações por meio de leituras, o compartilhamento de saberes e experiências de forma coletiva com outros casais grávidos e profissionais de saúde nos grupos, nas visitas e nas consultas de pré-natal e o envolvimento do pai nos preparativos para acolher o bebê, como apontam as falas.

O próprio sentimento do pai, se ele está grávido. Por mais que não possa participar fisicamente, ele pode de outras maneiras, buscando informações na internet, perguntando ao médico ou a quem for (Mãe Cavalo Marinho).

Curtindo cada minuto [...] Desde pintar a parede do quarto, montar o bercinho (Pai Cavalo Marinho).

Vou ao grupo de gestante também. [...] conversamos bastante sobre o assunto. Ler algumas coisas, prestar atenção em reportagens na televisão sobre bebê (Pai e Mãe Avestruz).

Ter orientações e informações sobre trabalho de parto e cuidados com a parturiente e conhecer seus direitos são fundamentais para que o homem assuma uma participação mais ativa no processo de nascimento, reduza as ansiedades e os medos, apoie, dê segurança e tranquilidade à mulher. A participação de homens nos encontros de casais grávidos ou grupos específicos para pais facilitam a inclusão do homem no processo de nascimento. Os homens apresentam demandas distintas e distintas das mulheres, e este fato precisa ser reconhecido pelos profissionais. O reconhecimento das necessidades masculinas e a chance de discutir as ansiedades, especialmente relativas à definição do papel paterno, nas atividades educativas no pré-natal podem 
proporcionar ao homem uma transição mais suave para a paternidade ${ }^{(15,18)}$.

A motivação, o estímulo, a abertura da mulher e a valorização da figura paterna pelo casal foram colocadas como possibilidades determinantes para inserção e participação do companheiro no processo de nascimento. Colaboraram para isto, a disponibilidade de tempo/horário de alguns pais, o companheirismo e a cumplicidade com sua mulher.

Fazê-lo participar. Quando ela começa a se mexer, eu digo: vem, vem... . No ultrassom.... É legal ele sentir, ver que realmente tem alguém (Mãe Cavalo Marinho).

O desejo e o estímulo das gestantes para a participação dos pais são fundamentais para inclusão do pai e satisfação do casal frente à nova experiência ${ }^{(18)}$.

O estímulo de alguns profissionais de saúde, sobretudo dos enfermeiros, para os pais participarem das consultas pré-natais e a oferta dos grupos educativos coletivos foram destacados como fatores para inserção do pai no processo de nascimento.

Senti incentivo sim por parte do médico e, principalmente, das enfermeiras e de vocês (acadêmicas de enfermagem). Eles falaram, assim, que é muito bom a gente participar, aprender mais a respeito da criança, do neném (Pai Avestruz).

O enfermeiro é um dos elementos-chave no acolhimento do homem/pai na unidade de saúde e no estímulo a participação ativa do pai no processo de nascer ${ }^{(7)}$.

Como agentes multiplicadores e de mudança, os profissionais de saúde, entre eles, o enfermeiro, precisam abrir oportunidades para discutir as relações de gênero no cotidiano do casal, a distribuição equitativa de responsabilidades e a implementação de um modelo menos preconceituoso e estereotipado sobre o masculino e o feminino, fundamentais para a constituição de relações mais igualitárias entre os sexos e para compreensão da nova maternidade e paternidade que emerge ${ }^{(7,20)}$.

As práticas educativas coletivas no grupo de gestantes ou casais e no âmbito individual nas visitas domiciliares, destacadas pelos participantes nos depoimentos, e percebidas no cotidiano pela aderência e participação ativa dos casais, foram consideradas fatores relevantes para inclusão do pai no processo de nascimento.

Estas atividades educativas contribuiram para maior compreensão do pai sobre processo de nascimento, aprendizagem dos cuidados com a mãe e bebê, preparo para o parto, fortalecimento dos potenciais e habilidades do casal e do pai para fazer escolhas e ajudar a companheira na gestação, parto e pós-parto. Isto contribuiu para maior segurança, tranquilidade e autonomia do casal. Estimulou o exercício da paternidade desde a gestação, ajudou na formação do vínculo mais precoce entre pai e filho, facilitando a transição do imaginário para o concreto.

No começo ele dizia que não tinha caído a ficha [...]. Agora ele beija a barriga, já fala. Antes tinha uma certa distância (Mãe Pinguim).

Eu achei um serviço de primeira. Me senti importantíssimo. Chique (Pai Cavalo Marinho). Ajudou nos cuidados da criança e com a mãe. Coisinhas básicas, pequenas, mas de extrema importância (Pai Peixe Palhaço).

É bom saber como eu vou agir. Isso me deu segurança, me deixou tranquilo. (Pai Lobo Guará).

Consegui adquirir informações para ajudá-la na gestação, acompanhá-la no médico e nos cuidados com o bebê. As massagens também (Pai Avestruz).

A socialização de saberes favoreceu 0 relacionamento entre o homem e a mulher, uma vez que propiciou maior proximidade do casal. Ao conhecer todo o processo de nascimento, o homem passou a perceber e compreender melhor os sentimentos da companheira, preocupar-se com ela e valorizá-la. Da mesma forma, a mulher pôde perceber a importância do homem no processo, o que contribuiu para que a mulher ampliasse espaços e estimulasse a participação paterna. Reforçou a importância do homem como integrante da rede de apoio à mulher na gestação, parto e pós-parto. Isto é visível nas falas dos participantes.

Acho que eu dei mais valor ainda a ele. O quanto é importante o pai está do lado, participar. Eu vi realmente a diferença. Ele se preocupava mais com ela (bebê), agora ele se preocupa comigo também (Mãe Lobo Guará). Nossa, está mais perto, mais carinhoso e calmo. Ele escuta mais (Mãe Peixe Palhaço). 
O desenvolvimento do processo educativo propiciou ainda o vínculo com os cuidadores e aproximou a comunidade dos serviços de saúde.

Mudou tudo, ele se envolveu mais. Eu falava que eu tava com uma dor aqui... Sabe, ele se fazia de desentendido (risos). Agora, não. Pergunta para as gurias se é normal. Ele se envolveu mais com a gestação e com o bebê (Mãe Lobo Guará).

O processo educativo constitui-se em oportunidade para estimular a reflexão sobre diferentes papéis sociais e subsidiar transformações de atitude frente à maternidade e paternidade, oportunizando aos futuros pais acolher o novo ser de maneira tranquila.

\section{CONCLUSÕES}

A partir dos resultados deste estudo, constataramse dois significados de "ser pai" do ponto de vista dos casais grávidos: o pai provedor da família e o pai afetivo e envolvido com a gravidez, processo de nascimento e cuidados com os filhos. Os dois significados convivem por vezes de forma conflituosa e antagônica e se transformam de forma gradativa com as novas mudanças sociais e de papéis do homem e da mulher, ampliado e resignificando o papel de pai.

Neste processo para exercitar a paternidade o homem confronta-se com o novo, apresenta sentimentos ambivalentes. Na medida em que ele se envolve com a gravidez, com sua companheira e filho e procura se inserir no processo, constrói e sedimenta o papel de pai. Os fatores limitantes para a participação do pai e exercício da paternidade foram: a questão cultural, a não liberação do homem do trabalho, o desconhecimento dos homens de seus direitos, a falta de informações, a postura de algumas mulheres que inconscientemente não deixam seus companheiros atuarem, a inexistência de serviços destinados aos homens, a descontinuidade e reduzida oferta de atividades educativas, a incompatibilidade de conciliar os horários do trabalho e os das consultas, e o despreparo dos profissionais para inclusão do pai. Entre os fatores favoráveis destacaram-se: os novos papeis sociais do homem e da mulher; a nova atitude da mulher, de abertura e valorização da figura paterna; os direitos conquistados, a disponibilidade de tempo e interesse dos pais; o desenvolvimento do processo educativo na atenção básica, o estímulo dos profissionais, em especial os enfermeiros, para a participação e inclusão do pai já no pré-natal.

O processo educativo, desenvolvido nas visitas domiciliares e nos grupos de casais grávidos, configurouse como uma estratégia para maior compreensão do processo de nascimento, inserção do pai desde o prénatal, ampliação da autonomia do casal e reflexão e exercício da maternidade e paternidade. O estudo reforçou a importância do papel do enfermeiro como facilitador do processo educativo e integrante da rede de apoio ao casal grávido e seus familiares. A mulher tem um papel fundamental na inserção do companheiro e estímulo à participação no processo de nascimento. O profissional de saúde pode contribuir, inserindo o homem desde a gestação, nas consultas e práticas educativas.

A pesquisa convergente assistencial possibilitou pesquisar e ao mesmo tempo refletir, socializar conhecimentos e experiências e introduzir mudanças com vistas à participação do pai no processo de nascer.

A construção do conhecimento sobre a temática reforçou a necessidade de flexibilizar e ampliar os horários de consultas e grupos e de capacitar profissionais para inserção do pai na gestação. A pesquisa ampliou o estudo da arte e a reflexão sobre o fenômeno e pode servir de subsídio para mudanças nas práticas de saúde do enfermeiro na atenção básica. O estudo mostrou o quão relevante e atual é o tema e trouxe contribuições valiosas para a inserção do homem no processo de nascimento Recomenda-se que seja replicado em outros cenários e ampliado, incluindo outros aspectos sobre a temática.

3. Silva MR, Piccinini CA. Sentimentos sobre a paternidade e o envolvimento paterno: um estudo qualitativo. Estud.psicol.

(Campinas). [Internet] 2007. [cited 2008 jun 25);24(4):61-573. Available from:

http://www.scielo.br/pdf/estpsi/v24n4/v24n4a15.pdf.

4. Borsa, JC; Nunes, MLT. Aspectos psicossociais da parentalidade: o papel de homens e mulheres na família nuclear Psicol. argum.

\section{REFERÊNCIAS}

Intregrare; 2010

2. Freitas WMF, Coelho EAC, Silva ATMC. Sentir-se pai: a vivência masculina sob o olhar de gênero. Cad. Saúde Pública. [Internet]. 2007 [cited 2008 abr 16]; 3(1):137-145. Available from:

http://www.scielo.br/pdf/csp/v23n1/14.pdf. 
[Internet] 2011 [cited 2012 abril 4];29(64):31-39. Available from: http://www2.pucpr.br/reol/index.php/PA?dd1=4524\&dd99=view. 5. Benczik EBP. A importância da figura paterna para o desenvolvimento infantil. Rev. psicopedag. 2011; 28(85): 67-75. 6. Freitas WMF, Silva ATMC, Coelho EAC, Guedes RN, Lucena KDT, Costa APT. Paternidade: responsabilidade social do homem no papel de provedor. Rev. Saúde Pública [Internet]. 2009 [cited 2012 sep 30];43(1):85-90. Available from: http://dx.doi.org/10.1590/5003489102009000100011 .

7. Costa, OSC et al. Participação do homem/pai no acompanhamento da assistência pré-natal Cogitare Enferm. 2009;14(1):73-8.

8. Calderón Benítez, NM; Ruiz de Cárdenas, CH. La gestación: periodo fundamental para el nacimiento y el desarrollo del vínculo paterno Av. enferm; [Internet] 2010 [cited 2012 sep 30];28(2):88-97, jul.-dec. 2010. Available from:

http://www.enfermeria.unal.edu.co/revista/articulos/xxviii2 8.pdf. 9. Piccinini CA, Silva MR, Gonçalves TR, Lopes RS, Thantudge J. O envolvimento paterno durante a gestação. Psicol. Reflex. Crit. [Internet] 2004 [cited 2012 sep 30];17(3):303-14. Available from: http://dx.doi.org/10.1590/50102-79722004000300003.

10. Figueiredo W. Assistência à saúde dos homens: um desafio para os serviços de atenção primária. Ciênc. saúde coletiva. [Internet] 2005 [cited $2012 \mathrm{sep} 30$ ]; 10(1):105-9. Available from: http://dx.doi.org/10.1590/S1413-81232005000100017.

11. Oliveira, AG ; Silva, RR. Pai contemporâneo: diálogos entre pesquisadores brasileiros no período de 1998 a 2088. Psicol. argum [Internet] 2011 [cited 2012 abr 12]; 29(66):

353-360, jul.-set. Available from:

http://www2.pucpr.br/reol/index.php/PA?dd1=5293\&dd99=view.

12. Trentini M, Paim L. Pesquisa convergente-assistencial: um desenho que une o fazer e o pensar na prática assistencial em Saúde-Enfermagem. 2 ed. Florianópolis: Insular; 2004.

13. Zampieri MFM. Vivenciando o processo educativo em enfermagem com gestantes de alto risco e seus acompanhantes. Rev Gaúcha Enferm. 2001; 22 (1):140-166 14. Minayo MCS. O desafio do conhecimento: pesquisa qualitativa em saúde. 12rd ed. São Paulo; Rio de Janeiro: Hucitec-Abrasco; 2010.

15. Cavalcante M. A experiência do homem como acompanhante no cuidado pré-natal [thesis]. São Paulo: Escola de enfermagem da Universidade de São Paulo; 2007. 153 p.

16. Teykal CM, Coutinho MLR. O homem atual e a inserção da mulher no mercado de trabalho.Psico.[Internet] 2007 [cited $2012 \mathrm{sep}$ 30];38(3):262-268. Available from:

http://revistaseletronicas.pucrs.br/ojs/index.php/revistapsico/articl e/viewFile/2888/2183.

17. Giraldi J, Hashimoto F. Da concepção de gênero à concepção de paternidade: mudanças no homem do século XXI. Trivium rev. ele t. mult. ucp [Internet] 2011[cited 2012 sep 30;2(1):36-48. Available from:

http://www.ucpparana.edu.br/trivium/edicoes/n1v2/concepcao_gen ero giraldi.pdf.

18. Magnoni Reberte L, Komura Hoga LA. A experiência de pais participantes de um grupo de educação para saúde no pré-natal. Cienc. enferm.[revista en la Internet]. 2010 ucp [Internet] 2011[cited 2012 sep 30];16(1):105-114.Available from:

http://dx.doi.org/10.4067/S0717-95532010000100012.

19. Tomereli KR, Pieri FM, Violin MR, Serafim D, Marcon SS. Eu vi meu filho nascer: vivência dos pais na sala de parto. Rev Gaúcha Enferm. [Internet] 2007 [cited $2012 \mathrm{sep}$ 30];8(4):497-504. Available from:

http://www.seer.ufrgs.br/index.php/RevistaGauchadeEnfermagem/ article/view/3110/1716.

20. Tarnowski KS, Próspero ENS, Elsen I. A participação paterna no processo de humanização do nascimento: uma questão a ser repensada. Texto Contexto Enferm. [Internet] 2005 [cited $2012 \mathrm{sep}$ 30];14(esp):102-108. Available from:

http://dx.doi.org/10.1590/\$0104-07072005000500013.

Artigo recebido em 25/10/2010.

Aprovado para publicação em 13/12/2011.

Artigo publicado em 30/09/2012. 